his kidney technique upon a patient. This I was most pleased to do. Dr. Carelli came to the French Hospital on December 8th, 1921, and, in the presence of several radiologists, performed a perirenal inflation.

The apparatus has been described elsewhere, as also the method: all I need do here, beyond referring very briefly to the principles involved, is to give some personal impressions.

By ordinary radiography the lower lialf of the kidney can be shown, provided that the patient is well prepared. Under favourable circumstances, the whole organ may be distinguished, but the outline is often vague and difficult to differentiate from the surrounding parts; - this is moro especially the case when disease, such as tuberculosis or malignancy, is present. Nor can one by the usual methods demonstrate the suprarenal capsule. On the other hand, the injection of gas into the peritoneal cavity does not fully define the outlinc, as the kidney is an extraperitoneal organ. Dr. Carelli therefore resorted to the production of an artificial empliysema around the kidney itself, and ho informed us that he had carried this out several hundred times without accident of any kind.

Unfortunately there did not happen to be in the hospital at the moment any cases suitable from a medical point of view, so that the hope of demonstrating some actual pathological condition had reluctantly to be abandoned. However, with some difficulty I induced a normal subject to submit to the procedure.

\section{Mclhod of Procedure.}

The subject was made to lie face downwards on the $x$-ray couch and Dr. Carelli first took steps to find the transverse process of the second lumbar vertebra. This he did (1) by tracing the last rib to its junction with the spine and taking a point $2 \mathrm{~cm}$. below the angle and an equal distance from the middle line (the $2 \mathrm{~cm}$. is of cource an average measurement only); (2) by counting the spinous processes upwards from the fourth lumbar and taking a point millway between the second and first, as giving the required level.

The patient was a man of average build, weighing 11 st., and his bony landmatks were not difficult to feel; but Dr. Carelli explained that, in the case of a stout man, it is necessary to explained the prccess according to some of the well linown methods used in the case of foreign bodies.

'The site of the second transverse process having been ascertained, the skin was swabbed with iodine, and a fine platinum needle about $10 \mathrm{~cm}$. long was pushed in vertically until brought to a stop against the bone. This is landmark number one. Up to this point the patient felt nothing other than the prick of the needle. Having called our attention to the fact that the needle was actually against the process, Dr. Carelli proceeded to alter the irre point slightly forward and a little outwards, so that it slipped past the obstruction. He pushed the wards, so that it slipped past the obstruction. He pushed the needle in until he believed that he had reached the perinephric
areolar tissue. (The needle a ppeared to be buried to the extent of areolar tissue. (The needle a ppeared to be buried to the extent of
about $6 \mathrm{~cm}$.) He then waited a moment to see if any blood came out tbrough the needle. Had this occurred, it would have meant that a vessel was punctured, and a reinsertion would have been necessary. This is point number two. Having satisfied himself as to this, he vext connected the needle with the manometer of the oxygen container. The latter is similar to the apparatus used for axygen container. 'The latter is similar to the apparatus used for artiticial pnemmothorax, and need not be described. The manometer readings constitute a third, and a very important, point
in the technique. As soon as the connexion was made one saw in the technigue. As soon as the connexion was made one saw tion-the opposite to what would have happened had the needle been in the pleural cavity. It appears that sometimes the manometer column dces not move even though the needle point is in the perirenal space. If no movement occurs, and the needle seems to be at a proper depth, a few centimetres of gas shculd ke very to be at a proper when the manometer will give the usual carefully introduced, when the manometer will give the usual be produced at once, and the occurrence of pain (other than a dull ache) is always an indication that a retrial must be made.

Having pointed out these facts to us, Dr. Carelli closed the manometer counexion and opened the stopccck counec:ing the needle with the oxygen chamber. He then proceeded to inject the gas very slowly. The patient complained of an increasing ache in his loin and a his loin, and ar Calli said this was sufticient in most cases he stopped the pump and pulled out the needle. The latter is of he stopped the pump and pulled out the needle.

Dr. Carelli's usual procedure is then to turn the patient on to his back and take plates from above with some degree of compression. I asked if we might first screen, and we did so. The kidney, like an island in a lake of air, was plainly seen by all, and any gross plate was then taken in this position-that is, tube below, patient on face.

The patient was now asked to turn over, and did so withont much apparent discomfort. A plate was taken with the tube above, the apparent discomfort. A plate was taken with the tube above, the patient on his back; he did not object to a moderate amount of made him bend his back in various directions to show that the remaining discomfort was slight.

The patient walked up some steps and along a corridor to a waiting taxi, and I took hin to my rooms, as I wished to secure some radiographs with my own apparatus. A preliminary screen exanination, one hour after the original injection, showed no apparent diminution in the intlated area. Oxygen had been usert, as it was the only gas available. Dr. Carelli himself always uses $\mathrm{CO}_{2}$ because it is absorbed within an hour. But for the beginner oxygen presents certain advantages.

To sum up my personal impressions :

The essential points of the teclinique aie-(1) Use of a fine needle; (2) accurate location of the transverse process of the second lumbar vertebra; (3) proper direction of the needle after it has struck the. process; (4) use of needle open so long as it is being advanced: this permits observations of punctured blood vessels; (5) sound judgement as to deptl of insertion; (6) determination of entrance of needle point into perirenal tissue by manometer readings; (7) slow injection of gas; (8) quautity not to exceed $500 \mathrm{~cm}$.

As to indications for use, any case in which there are signs or symptoms suggestive of kidney trouble, and in which clinical and ordinary radiographic examination does not completely clear up the diagnosis, should be investigated by thịs method. Alterations in shape, size or density are at once made clear, also calculi too small or faint to show in the usual manner. A wide field should be the investigation of altera. tions in the adrenal body-thus the method is not limited tc strict!y urological cases, but should be used in elucidating certain disorders of the ductless glands.

As to risks, there may be a theoretical possibility of setting up perirenal cellulitis, but no suggestion of any ill effect has occurred in Dr. Carelli's practice. On the other hand, the procedure may turn out to have therapeutic uses, on the lines of Colonel Rost's paper in the British Medical Journal of December 10th, 1921. Personally, having carefully considered Dr. Carelli's radiographs, and seen lis procedure upon the living subject, I have no hesitation in recommending the method as one of very great value.

\section{1)EEP X-RAY THERAPY IN MALIGNANT JISEASE. \\ NOTES OF'A VISIT TO ERLANGEN.*} BY

J. CURTIS WEBB, M.A., M.B., B.CH., HONORARY RADIOLOGIST, GLOUCESTER INFIRMARY.

During a visit to Erlangen last September I was able tc make certain observations which I propose to relate. I wil! consider the principles underlying this form of $x$-ray therapy under three lieads: (1) Physical, (2) biological, (3) therapeutic.

\section{Physical.}

Wintz defines his unit shin close (U.S.D.) as that dose of rays, generated at a special voltage $(180,000$ to 200,000 volts; by a special tube, and filtered through $0.5 \mathrm{~mm}$. zinc, which, at $23 \mathrm{~cm}$. distance from the shin, produces on the area treated a red blush after five to eight days, and distinct tanning after four weeks. 'This dose he calls 100, and he expresses in percentages the amount absorbed, and therefore active, at varying depths below the surface. He estimates these percentages by the iontoquantimeter of Szilard, which depends for its action on the fact that electrically charged air is discharged by $x$ rays falling thereon at a rate directly proportional to the quantity, irrespective of quality-tliat is hardness-of such rays. It consists of a heavily insulated wirc, one end of which passes into a closed cardboard chamber (of Bergmann's camera) like a large tcst tube. The other end is connected to an electroscope, one leaf of which is fixed, and the other held lightly against it by a fine hair-spring. When the whole is cliarged by a small influence machine the leaves separate. If now $x$ rays be allowed to fall on the camera the air therein is discharged and the leaves come together. The time taken by the movable leaf to pass over a scale lying under it is talien as a comparative measure of the amount of rays falling on the camera. For example, if filtered ays fall direct on the camera, and the electroscope leaf talses 9 seconds to travel over the scale, or in other words to discharge the air in the camera, and if now a box of water, which has the same co. efficient of absorption of $x$ rays as the human tissues, of a thickness of $10 \mathrm{~cm}$., be interposed between the $x$-ray telose and the camera, and it is found that the time taken is 54 soénds, the ratio of the amount of rays received by the cameia in the

* Substance of a paper communicated to the Gloucestershire Branch or the British Medical Association. 
two cases is 54 to 9 , or 6 to 1 ; that is to say about 17 percent. is still active after passing through $10 \mathrm{cccm}$. of water. Such an instrument can bo used to obtain an accurate indication of the active rays passing through any desired thickness of water or human tissue.

The bundle of rays given out from an $x$-ray tube consists of waves of varying lengths. The softest rays have a wave length of 1 Angstrom unit (A.U.), which is taken as the unit of wave length measurement; and the hardest are 0.25 to 0.14 A.U. The penetrating power of the softer rays, though they have biological activity, is slight and varying, and the ain of Professor IVintz has been to obtain a radiation that would be penetrating and homogeneous.

To obtain the first of these two qualities it was necessary to secure an $\dot{x}$-ray tube that would not only emit a ray bundle which containcd the maximum of hard, that is ponetrating, rays, but this tube must be capable of sustaining a steady output of these rays for several hours on end. This has been secured, both in the forin of the Coolidge tube, and a special form of self-hardening gas tube, with an ingenious method of automatic regulation, which secures the maintenance of a fixed hardness for many houis. To secure an output of these hard rays it is necessary to pass through these tubes a current of far higher voltage than we have been in the habit of employing hitherto. The optimum voltage, taking many other factors into consideration, including the greatly enhanced cost and destructibility of tubes according to the increased voltage, has been found to be 180 to 200 kilovolts; that is, if at these voltages the absorption of rays at $10 \mathrm{~cm}$. deep is 18 per cent. of the unit skin dose; it is only 19 per cent. at 250 kilovolts. 'Tho special apparatus devised to give this output, and to maintain it for long periods withcut breaking down, differs from those in general use in that the latter are designed to pass the maximum current through a medium soft tube for a short time, while the Erlangen technique requires the passage of a small quantity through an intensely liard tube at a very high voltage for long periods.

If dosage is to be accurate it must be capable of being measured-that is to say, it must be possible to state in terms of percentage wlat proportion of the unit skin dose is absorbed; or active, at varying depths in the tissues. To attain this the ray must be practically homogeneous, a ray, that is, which has been so thoroughly filtered from the rays of longer wave length that, in its passage through the human tissues or other media, it is not further changed in quality, or, as a corollary, is absorbed.in fairly uviform percentages by each equal amount of the tissue or other substance. This homogeneity is obtained by filtration of the ray, and Wintz states that with the special gas tubes referred to above it can be secured by using a filter of $0.5 \mathrm{~mm}$. of zinc (=12 mm. aluminium); in tubes of the Coolidge pattern working at the same voltage and with the same equivalent spark gap it is necessary to use $4 \mathrm{~mm}$. of aluminium in addition to the $0.5 \mathrm{~mm}$. of zinc. When these hard rays pass through the tissues they undergo a weakening, or sloss, through each successive centimetre. This loss is maike up of absorption plus dispersion; dispersion takes place through the " secondary ray." Wintz divides these rays into three groups:

1. Beta rays, which are actually formed in the tissues; they have a small range of action, but are, however, extremely potent, and play a very important part in deep therapy.

2. Fluorescent rays, which are very soft, are caused by the rays impinging on the filter or skin. In deep therapy they can be neglected unless the filter is placed directly on the skin.

3. Scattered rays, which have the same quality as the primary ray, and may be regarded as automat:cally generated additions to this ray. They are the most important of the secondary rays.

Their generation is increased as the voltage increases, as the diameter of the bundle of incident rays is increased, and as the rays penetrate deeper and deeper into the tissues.

These facts can each be proved by first calculating what should be the active dose at any given depth under given circumstances : if the accuracy of these figures be tested by the iontoquantimeter it is found there is a definite error, and that the actual is greater than the calculated amount. 'This eryer is due to the progressively increasing action of the seggndary rays. It is found that the reiative absorption at a given depth is increased the further the anticathode is removed from the skin. But this increase is obtained only hw oreatly augmenting the time of exposure. For example, if the U.S.D. is reached in 35 minutes at a distance of $23 \mathrm{~cm}$. it will require 165 minutes at $50 \mathrm{~cm}$. and 372 minutes at $75 \mathrm{~cm}$., or over 6 hours, because the intensity of $x$ rays, like that of light, varies inversely as the square of the distance. Nevertheless, in comparatively süperficial cancers, for example, scirrhus of the breast, vulva, etc., where tho cross fire method of application is difficult or impossible, where the tumour is very large, or where it cannot be accurately located, this method of application is often necessary.

Wintz states the time of irradiation is not shortened by increasing the quantity (milliampèrage) of current passing through the tube. The optimum is about 2 milliampères. as appears from the following table, for a Furstenan Coolidgo tube :

M.a. through
Tube.
1.0
1.5
2.0
2.5
3.0
4.0
5.0
6.0

$\begin{array}{lll} & & \\ \cdots & \cdots & \cdots \\ \cdots & \cdots & \cdots \\ \cdots & \cdots & \cdots \\ \cdots & \cdots & \cdots \\ \cdots & \cdots & \cdots \\ \cdots & \cdots & \cdots \\ \cdots & \cdots & \cdots\end{array}$

\begin{tabular}{cccc} 
& & \multicolumn{2}{c}{$\begin{array}{c}\text { Pcrcentage Dose } \\
\text { at } 10 \text { cm. de'p. }\end{array}$} \\
$\ldots$. & $\ldots$ & $\ldots$ & 24.2 \\
$\ldots$ & $\ldots$ & $\ldots$ & 24.0 \\
$\ldots$ & $\ldots$ & $\ldots$ & 24.2 \\
$\ldots$ & $\ldots$ & $\ldots$ & 23.4 \\
$\ldots$ & $\ldots$ & $\ldots$ & 23.0 \\
$\ldots$ & $\ldots$ & $\ldots$ & 21.0 \\
$\ldots$ & $\ldots$ & $\ldots$ & 19.0 \\
$\ldots$ & $\ldots$ & $\ldots$ & 18.0
\end{tabular}

It has been argued that because the rays are so hard they penetrate without action, but the fact seems to be that it is because the rays are hard thai they set up the important secondary, or scattered radiations. In this country we usually employ 4 to $6 \mathrm{~mm}$. aluminium to filter the rays, instead of the equivalent of 12 to 16 as at Erlangen, and the voltages used are too low to generate them in sufficient quantities.

As to the relation of radium to deep $x$-ray therapy, it is to be noted that the action of radium is losal, and does not extend beyond, at the outside, $3 \mathrm{~cm}$. from its source. It follors, therefore, that to attack a tumour of any size a number of tubes must be buried in the growth, which will each produce an intense local necrotic action, but its area of influence rapidly diminishes till, at about one inch away, the dose received by the cancer cells is no longer lethal, but may be actually stimulating. If radium could be obtained in larger quantities it might be different, but as things are its use at Erlangen has been entirely abandoned, save where a purely local action, as in a malignant stricture of the oesophagus, is required.

\section{Biological.}

The theory on which the efficacy of $x$ rays on malignant growths and on ovarian tissue depends has hitherto becn based on the action of the rays in splitting up lecithinin which cancer cells are exceptionally rich-with the liberation of cholin, an intense poison, which when set free in the cells kills them. Wintz has found that with his technique, and calculating the U.S.D. at 100, the percentage required to destroy the following tissues is-for

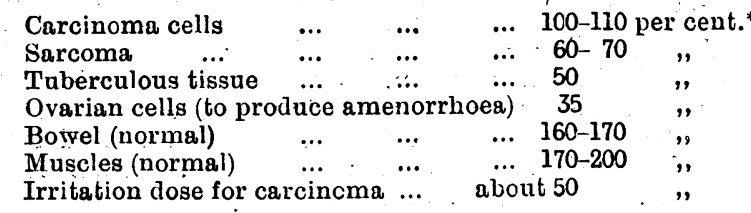

* Minimum, s0 per cent.

The following theory has been evolved by Dr. W. J. Turroll, of Oxford. It fits in with the work of Dr. Rigaud, Director of the Biological Laboratory of the Paris Radium Institute, and I am much indebted to Dr. Turrell for permission to mention it before his forthcoming work-in which it is more fully elucidated -is actually published. ${ }^{1}$

Kohler has obtained microphotographs of the dividing nuclei in the gill plates of the salamander by ultra-violet rays, and has shown that the chromatin substance in theso nuclei is so opaque to waves of very short length as to appear as though it were deeply stained; he has proved the complete absorption of these short wave lengths by the chromatin. Light is only active when it is absorbed and it is only absorbed when its wave length is in resonance with-that is to say, when its vibiation corresponds with-those of the atoms on which it falls (law of Grotthus).

Furtlier, Rigaud has shown that certain cells are very sensitive to hard $x$ rays and the gamma rays of radiun. A subcutaneous lymphosarcoma can be destroyed without producing any skin changes except the falling out of the 
hairs; this result must be due to a selective action of the rays on two particular types of cells - the sarcoma cells and the generating cells of the hair follicles. This selective action appears to depend, not on the nature of these cells, but to be due to certain states or physiological moments in their life, the best. known of which is the state of reproduction. The special radio-sensibility of cancer cells is due to their indefinite reproduction. The essence of reproductive power is in the cliromatin, and hard rays poison chromatin, acting probably by a process of oxidation or reduction, so setting free a ferment or toxin. If this toxin is liberated in small quantities-as by a slight action of the rays-the action on the other cells would appear to be stimulating; if the action is profound, cell death follows.

This hypothesis of a toxin explains the latent period before the effects of $x$ rays manifest themselves, and as the presence of a toxin in the blood always tends to the forma. tion of a specific antitoxin, there is here an explanation of the fact that in such-constitutional diseases as leulraemia much benefit is often derived from the first course of raving, while each subsequent course seems to be less and less efficacious. It is known that when the blood of a leukaemic patient is submitted to $x$ rays leucopenia follows, and attains its maximum after an interval of five to ter days. It is pro-' bable that this leucopenia is due to a leucolysin caused by the toxin formed in the blood in consequence of the action of the rays on those nucleated white blood corpuscles whose nuclei are in a specially radio-sensitive state at the time they are exposed to the rays, that is to say, those whose chromatin granules are undergoing karyokinesis.

Curschmann and Gamp have proved that the serum of a leukaemic patient, subjected to repeated raying for a long period, would, if injected into the blood of another leukaemic patient who had not been rayed, cause a destruction of leucocytes, but that the leucocyte count returned to what it was nore rapidly after each injectiou.* Can this be explained save on the assumption of the formation of a "toxin" and "antitoxin"?

If further research serves to establish this theory as the true explanation of the action on the tissues of waves of rery short length, does it not open the question whether all our methods of $x$-ray therapy - at any rate, as far as attacking deeper structures is concerned-have not been fundamentally wrong? It has been the custom to use divided doses of medium hard rays spread over a period, each dose being far short of the full letlial dose. In these circumstances have we not frequently only succeeded in creating so much toxin as to stimulate the remaining cells to further activity, and, by allowing time for the production of the antitoxin, to thereby minimize or destroy the value of subsequent applications?

Another intensely interesting speculation which arises is whether it would bo possible to ray carcinomata, either artificially produced or naturally occurring in animals, and thus load the blood of the animal with the specific toxin, which could then be injected into human beings, either as a prophylactic or curative agent. There is a strong analogy between such a procedure and the production of diphtheria antitoxin in horse serum. A furtlrer question is whether it is possible, prior to treatment, to secure that the maximum number of the growing cells of the tumour should be in the physiological moment of reproduction. This might be effected by giving preliminary small doses of rays designed to liberate so much toxin as should be a stimulant. Latterly Wintz had been administering to all his malignant cases a preliminary copper ionization, with a view to the introduction of copper ions into the growth, so as to secure an increase of secondary radiations in the tumour. The majority of electro. therapists are agreed that it is impossible to introduce ions from without deeply into living tissue; yet Wintz claims benefit from his ionization. May it not be that, just as intrauterine, or even percutaneous applications of the constant current will often cure amenorrboea, or delayed or scanty menstruation, by stimulating the cells of the Graatian follicles, so the passage of a constant current will stimulate karyokinesis in the cancer cells, and thus bring the maximum number possible into a radio-sensitive condition? For this purpose only a mild, and therefore painless, current would be required.

\section{Therapeutic.}

This deep therapy has been used successfully in the treatment of carcinoma, sarcoma, tuberculous affections of the

\footnotetext{
* Wintz has succeeded in inducing a menorrhoea in a patient suffering from menorrhagia by a similar course of injections.
}

peritoneum, bones, glands, etc. ; to produce amenorrhoea and shrinkage of the growth in fibroids; in leukaenia and other blood diseases, and in hypertrophy of the prostate.

It is possible to determine by the iontoquantimeter the exact percentage of the U.S.D. that is active at varying depths in the tissues. Thus, with the U.S.D. at 100, and with apparatus and tube functioning well, the active dose at $10 \mathrm{~cm}$. deep is about $18 \mathrm{per}$ cent. Now, the uterus is situated at about the cent:e of the circumference of the lower abdomen and approximately $10 \mathrm{~cm}$. from the skin. If we take the lethal carcinoma dose as 110 per cent. U.S.D., it is obvious that, if treatment be applied from six or seven ports of entry, the rays being directed on to the uterus, the skin in each area will only receive the U.S.D., but at the ceutre of this con. verging bombardment a total of $6 \times 18$ or $7 \times 18$-that js, 108 to 126 per cent. - will be reached. Similarly, as tlie dose at depths other than $10 \mathrm{~cm}$. is equally well known, it is but a matter of calculation, and consequent arrangement of the cross-fire, to secure the "carcinoma dose" on to any malignant disease so situated that the cross-fire method can be employed.

In malignant disease situated in or closely under the skin and where, therefore, this cross-fire method is not available, the problem is totally different. Let it be supposed that the case is one of scirrhus of the breast, or of vulvar carcinoma, where the disease extends only 3 to $5 \mathrm{~cm}$. deep. Every cell of sucl a growth must receive at least the minimum dose $(90$ per cent. U.S.D.), but, with the $23 \mathrm{~cm}$. focus distance and field of $6 \times 8$, the dose received by the cells at the lowest part of the growth is only about 60 per cent., and the irritation close, which causes an increase in the growth of cancer cells, is just about this figure.

Seitz and Wintz have found by experiment:

1. That increasing the distance of the anticathode from the skin increases the percentage of rays that are active at a giren depth. Thus at $3 \mathrm{~cm}$. deep, and usiog a field $6 \times 8 \mathrm{~cm}$., the percentage of rays absorbed is as follows:

$$
\begin{aligned}
& \text { If the anticathode is } 23 \mathrm{~cm} \text {, from the skin } \quad \ldots \quad 60 \mathrm{prcent} \\
& \begin{array}{l}
30 \mathrm{~cm} \text {. } \\
50 \mathrm{~cm} \text {. }
\end{array} \\
& 66^{60} \mathrm{p} .1
\end{aligned}
$$

2. They have further proved that the depth dose is improved by increasiug the size of the impact field. Thus at $3 \mathrm{~cm}$. deep, and at $30 \mathrm{~cm}$. distance, the percentage absorbed is as follows :

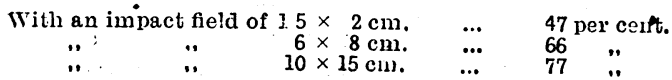

3. By a combination of these two factors-that is to say, by increasing both the distance of the tube from the skin, and also the impact field, it has been proved that at $3 \mathrm{~cm}$. deep :

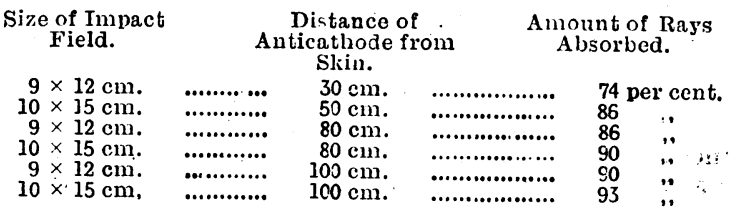

It is thus seen that it is possible to reach the minimal "carcinoma dose" even in the lorver lying cells of superficial cancers by greatly increasing both the field of impact and the distance of the anticatlsode, but this can only be attained by enormously augmenting the time of exposure. If at $23 \mathrm{~cm}$. the U.S.D. is reached in forty minutes, at $80 \mathrm{~cm}$. the time required will be approximately eight hours. As far as possible the dose lethal to the cancer cells is given at ono sitting, and the after-effects on the blood are combated by injections of one of the arsenic preparations.

The most important matter is to clecide how far this treatment is an adjurant to, or substitute for, operation. At Erlangen operation is practically entirely dispensed with, save in cases of primary carcinoma of the ovary, except where it is required for a subsidiary purpose-for example, colostomy before treating a carcinoma of the rectumi to ensure rest to and absence of irritation of the part, or gastro. enterostomy, or other short-circuiting operation, where obstruction is threatened.

Personally, I am uncertain whether at the present timo the results of this deep $x$-ray therapy have yet reached such a point of certainty that it is advisable, in the patients' interest, to dispense with operations, but $I$ am convineed that the severity of the operations can be minimized In cancer's of the uterus ana cervix I believe the best treatment to be pre-operative raying. After six weels the patient should be re-examined, and the local disease will then 
probably be found to be on the road to cure, and the para. metria can be attacked. 'If operation be necessary, certainly Wertheim's is not required.

In scirrhus of the breast I believe the local removal of the giowth to be desirable, but not the removal of the axillary ylands. By talking away the filters one tends to spread inetastasis, but these cases should have a pre-operative and a post-operative raying.

Cases of malignant disease may, from the point of view of tricatment, be divided into four classes : (1) Easily operable; (2) operable, but where there is every probability of there bcing inoperable extension of the primary growth; (3) hopeless for operation owing to position-for example, head of the pancreas, spinal cord, etc.; (4) inoperable owing to fixation of organs, extension of the disease, etc.

In Class 1 I believe in operation, followed by decp raying, and in Classes 2 and 3 in deep therapy alone; in Class 4 it is very difficult to decide. Nothing, save perhaps alleviation, can be hoped for from deep therapy, and, after the position has been fully explained to the patient or his family, the decision must rest with them.

When I was in Erlangen I asked for statistics, but was told that, at any rate as far as malignant cases were concerned, it was as yet impossible to give definite figures. The reason is crident, for this form of treatmont was begun only a short time before the war broke out, and was then in the purely experimental stage. During the war, though Professurs Seitz aud Wintz were able to carry on some experiments, they were not able to obtain all the necessary instruments to carry out treatment on a large scale. Investigations were pursued to ascertain the best form of generating apparatus, of filters and of tubes, to find out the exact dosage that would ensure the cessation of the menses, and would cause the death of malignant and other cells. The former result has been definitely attained. Wintz has published a report of 500 cases of uterine haemorrhage, due to fibromyomata, the menopause, and other causes, which have all been cured by one single treatment in each case. Dr. Ernest Stark, practising the same treatment in the provincial clinic at Weiden, reports 19 cases with only one failure, which was attributed to the use of an insufficiently powerful apparatus.

The failure or success of applications for such purposes is a) most at once evident, but the position is different when the results of the treatment of malignant disease are under consideration. To speak positively on the subject of "cure" the standard of five years' freedom from recurrence after treatment is generally accepted; consequently cases treated subsequent to 1917 . must be ruled out. But it was only about this date that the technique was perfected, or tliat sufficient instruments, tubes, etc., could be secured to treat a number of patients sufficient to afford the required data.

Again, it is to be remembered that the earlier a malignant case is subjected to deep $x$-ray therapy the better is the prognosis. But it is just these early cases that are also best from a surgical standpoint, and it is only natural that some time must elapse before an old and accepted treatment is supplanted by a newer one. Patients with cancer of the fomale generative organs go direct to the gynaecological clinic, of which Professor Wintz is the director, and can therefore be rayed when in the early stages of the disease, but with this exception the majority of cases of malignant disease treated by deep therapy are either primary inoperable cases, or patients with secondary deposits or relapses. These cases are naturally more unfavourable than early primary ones, and hence statistics would not be nearly as good as if it were possible to select purely suitable patients-as surgeons are able to do.

I saw several cases of malignant disease of the cervix and uterus which had been rayed as long as three and a quarter years before, in which there was no evidence of the disease to be detected on examination, and the patients had put on weight, felt well and were able to work-in fact, were apparently "clinical cures." I saw a man who had had a large fixed tumour the size of half a cocoanut on the left side of the neck; an excised piece had shown it to be a lympho. sarcoma: He had been rayed twice, the first time ten months earlier. When I saw him the lump was about the size of half a tennis ball, painless, and freely movable. It was apparntly simple fibrous tissue. The man had lost his pain and dysphagia, and was well and working. A case of periosteal sarcoma of the head of the humerns showed, both clinically and by $x$ rays, an equally good result, as did a case of scirrhus of the breast treated two years previonsly. In none of these cases was any operation performed, $\epsilon$ xcept the removal of a small piece for diagnostic purposes.

The chief assistant at Wertheim's clinic in Vienna, who was at Erlangen at the same time as I, told me the results of this treatment in cancer of the uterus or cervix are so good that Werthein's operation is gradually being abandoned in that clinic; it must, however, be remembered that owing to the central position of the uterus in the body it is ideally placed for "cross-fire" application, which is the most favourable method.

It has not been possible to read all the literature-even if one could obtain it-which has in recent years been published in Germany on this deep therapy. Suffice it to say that analyses and criticisms of the method liave been produced not only by the Erlangen school itself, but also by such anthorities as Wernekrose of Bertin, Martius of Bonn Fraenkel of Freiburg, Döderlein of Munich, Stark of Weiden, and many othors. In most cases both successes and failures are impartially described and efforts made to explain the one or the other. From what I have read and what I learnt from those with whom I talked on the subject (and while in Erlangen I had the chance of diseussing the subject with the professor of gynaecology in the University of Barcelona, with the physicians in charge of the $x$-ray and radium department in the University of Stockholm, and with the chief assistant at the clinic of the late Professor. Wertheim of Vienna).I have formed the opinion that all who have had practical experience of the Erlangen treatment are most farourably impressed by it. As far as I can see, its detractors are those who have prejudged it on theoretical grounds, or on account of bias because of sensational publieations.

The general inferences to be drawn from publications-ani. among the writers are surgeons as well as radiologists-and from my own impressions may be briefly summarized as follows :

1. 'That this form of treatment is a fundamental and epoch. marking improvement on pre-existing methods of $x$-ray therapy, and is the technique to be adopted in all cases (other than purely superficial slin lesions) where this form of therapy is indicated.

2. That, as in all other treatments, the earlier a suitable case is treated, the better are the results.

3. 'That it is the treatment of choice in all cases of menorrhagix or metrorrhagia in patients over 38 , provided that suppurative disease of the tubes or ovaries be excluded. Eden and Provis (Lancet, February 12th, 1921) are in agreement with the use of $x$ rays in these conditions, though they differ from the German school in excluding cases of malignant disease. It must, however, be remembered that they were not employing the Erlangen technique.

4. All the foreign authorities agree as to the immense value in every malignant case of either pre- or post-operative raying, or both, according to circumstances, and the majority -excluding Professors Seitz and Wintz and their immediate disciples-recommend operation according to the conditions that I have laid down above.

5 . Great use is made of deep $x$.ray therapy in tuberculous disease of the glands, bones, joints, bladder, and peritoneum as an auxiliary to other treatments. If in tuberculous glands there be a caseous focus, such glands will break down under the treatment.

Personally I am convinced that this new therapy has opened up a fresh avenue of treatment, and has enormously increased the field for the curative use of $x$ rays. Much was hoped for, and much disappointment has been experienced in the past from $x$-ray therapy in malignant and other diseases, but the researches of Professors Seitz and Wintz into the production of homogeneous rays and their accurate measurements, and into the absorption of these rays at varying deptls in the tissues, and the practical results obtained at Erlangen and elsewhere have, I believe, carried us far along the road the end of which is the satisfactory treatment of that which was previously considered hopeless, and has simplified and expedited the cure of many other conditionsfor example, fibroids and menorrhagia-the treatment of which has, up to the present, lain solely in the province of surgery. The British Association for the Advancement of Radiology and Physiotherapy, in issuing a warning to the public in connexion with the Erlangen treatment for cancer, said :

"We are, however, of the opinion that a closer co-operation between the surgeon and the radiologist would lead to a clearer appreciation of the value of radiation in treatment, and that, in all cases, both surgery and radiation therapy should be considered with a view to making the fullest use of botk " 
Advance will only come by this closer co-operation. It is not enough for the surgeon to order pre-operative or postoperative raying as his speciul predilection dictates. Deep therapy opens a newer and a wider field, and establishes the position of the medical radiologist as one to be called into consultation with the surgeon over a case, and to co-operate with him in deciding whether it is one for operation, for deep therapy, or for both.

REFERENCE.

Principles of Electrotherapy and their Practical Application. By W. J. Turrell Oxferd-Medical Press.

\section{CASE OF TRYPANOSOMIASIS FROM PORTUGUESE EASI AFRICA APPARENTLY CURED. \\ BY}

GERRGE C. LOW, M.A., M.D., C.M., M.R.C.P.,

SENYOR FUYSICIAN, HOSPIT I FOR TROEICAL DISEASES, ENDSLEIGH

$$
\text { GARDENB, N.W. }
$$

AND

H. B. G. NEWHAM, C.M.G., M.D., M.R.C.P.,

WARDEN OF STCDIES AND DIR. CTOR OF PATHOLOGY, LONDON SCHOOL OF TROPICAL MEDICINE, N.W,

BEFore one can speals of a definite cure in human trypanosomiasis some years of perfect health mnst elapse after the cessation of all treatment. Suggestions, such as have recently been made, of curing patients by one injection into the spinal canal of salvarsanized serum are, to say the least, of doubtful value and tend to indicate that the maker of them is ignorant of the literature of the subject. Judged by the test of time indicated abore, howevcr, there are quite a number of cases of infection with Trypanosoma gambiense that have been treated in England with successful results and are still alive years after their infection. (Cases of Manson and Daniels.) It is right to state, neverthe!ess, that this happy result has not been attained in all cases even of that infection; we lnow of two patients who have died recently of sleeping sickness, even though well treated over prolonged periods of time.

In infection with Trypanosoma rhodesionse (including under this t.1.m Portuguese East African infections) the prognnis is is very grave, and down to the present date perhaps only one case of a European ${ }^{1}$ can be said to have been cured (Mr. H., a case of Dr. Daniels). We have recently heard that this patient is at present farming in Rhodesia and is enjoying perfect health. The next best result we know of to this was the case of G. (under the care of Sir Patrick Manson and Dr. Daniels); who lived for two years and three months after infection. Though thoronghly treated with antimony and atoxyl, this patient died of sleeping sickness with typical lesions in the brain.

We have now the records of another case, that mentioned in the title to our paper, who is still alive three years after acquiring the clisease in Portuguese East Africa, and who is at present apparently well and in a good state of health. One of us (H. B. N.) saw this patient in Dar-es-Salaam in 1918 and has already published a note about him, ${ }^{2}$ while later $\mathrm{Dr}$. W. A. Murray, under the heading of "Notes on the Successful Treatment of a Case of Sleeping Sickness," gave further details of his treatment and stay in Durban up to the time when he was transferred to tlee South African Institute for Medical Research, Johannesburg, on October 8th, 1919. From that time till April, 1921, when he was sent home to England, Dr. Watkins-Pitchford, the Director of the Institute, has had him under observation and has very kindly supplied us with the details of his stay there. Finally the patient reached England on May 17th, 1921, and came direct to the Hospital for Tropical Diseaseş, where he has been under our observation since.

\section{History of Case.}

The patient as or as can be judged, was infected about October 9 th, 1918 , in the Lugenda River valley while on the march between Alto Molucue and Ngomano, Portuguese East Africa. On October 15th he reported sick with a temperature, but rejoined his battalion on the 19th. On the 20th he noticed a swelling in the right axilla and was admitted into Ndanda Hospital on October 25th with a temperature of $102^{\circ} \mathrm{F}$. and treated as a case of malaria. From there he was transferred to Lindi Hospital (November 14th, 1918), where a patch of cutaneous erythema with infiltration was noticed in the right mammary region and a general adenitis was detected. the 16th by Captain Butler showed trypanosomes. On November 26th, 1918, the patient was sent to Dar-es-Salaam Hospital, where he was seen by one of us (H. B. N.). On arrival the patient was anaemic and stated he had lost weight. The pulse was rapid, th spleen just palpable. An erythematous rash was seen on the trunk. There were one or two well-marked rings, but generally the rash was of a blotchy character. No local oedema or adenitis was found. Keraadel's symptom was absent. There were no eye syniptoms. The temperature on admission was $100.8^{\circ} \mathrm{F}$

Examination of the blood: Total red cells, 2,672,000; total white cells, 4,800: lymphocytes 26 per cent., large mononuclears 17 per cent., polymorphonuclear's 51 per cent., eosinoplites 6 , per cent: cent., polymorphonuclear's 51 per cent., eosinopliles 6 , per cent.
Scanty trypanosomes were found. Treatment with intravenous injectious of antimony was at once begun, but the patient did not stand the first injections at all well. On January 9 th, 1919, he was transferred by hospital ship to Durban, where he passed under the care of Dr. Murray. On admission there the following points were noted by Dr. Murray.

\section{Dr. Murray's Notes.}

Weight 11st. 4lb., one stone below normal. Weakness is marked, but he can walk about, and sleeps and eats well. There is no oedema, no hyperaesthesia of muscles on pressure (Kerandel's sign), no cramps or pains in bones. The heart appears to be normal ; urine normal ; spleen enlarged. There is general glandular normal; urine normal; spleen enlarged. There

Blood smears: Numerous trypanosomes present, also B.T. malarial parasites. Blood count: Red cells, 3,300;000; 'vhite celles 5,500; haemoglobin 55 per cent. Differential count: Polymorphonuclears 40 per cent., large mononuclears 20 per cent., lymphocytes 24 per cent., eosinophils 6 per cent., mast cells 1 per cent. myelocytes 2 per cent., leucoblasts 2 per cent., broken nucle 5 per cent.; a few normoblasts were present. Blood pressure $120 \mathrm{~mm}$. $\mathrm{Hg}$.

A rabbit and guinea-pig were injected on January 28th, 1919, each with $1 \mathrm{c.cm}$. of the patient's blood. The rabbit showed trypanosomes after thirteen days, and died in ten weeks. The guinea pig flrst showed trypanosomes after eleven weeks, and died in nineteen weeks. The trypanosomes were pol ymorphic, and posterior nuclear forms were found. A prolonged course of treatment was commenced on January 21st, 1919, as recommended by Dr. Newham (see below), and this was kept up till the patient was sent to Johannesburg.

Dr. Wathins-Pitchford's Notes.

The patient was admitted into the South African Institute for Medical Research, Johannesburg, on October $8 \mathrm{th}, 1919$. Weight 11 st. $11 \mathrm{~b}$. He was kept under continuous observation and treatment until May 7th, 1920 by Dr. J. H. Harvey Pirie. The ment until May 7th, 1920, by Dr. J. H. Harvey Pirie. The examination of the daily blood specimens was undertaken by Dr.
Annie Porter, who found a few $T$. rhodesiense (many of which were degenerate forms) upon the day of admission and upon each day, with one exception, up to October 17th, 1919. The numbers were small, 3 per cubic millimetre at most. Although daily examinations (thick films) have been made from the last-mentioned date until April 8th, 1921, no further trypanosomes have been detected.

It is worthy of note that trypanosomes had not been detected in the blcod for forty days prior to admission to the institute, the last cccasion upon which Captain Murray, of Durban, found them being August 29th, 1919. Although treatnent had not been intermitted during these forty days, trypanosomes were found, as stated, upon each of the first eight or nine davs of the patient's stay in the institute. The question arises whether the cliange in altitude and temperature associated with his transference from Durban to Johannesburg had brought about the reappearance.

On May 7th, 1920, the patient was allowed to go home (Premier Mine, near Pretoria), the treatment being continued by Dr. Gow, daily b'ood specimens being sent to the institute for examination. The patient again attended the institute, this time as an outpatient, from Iecember 18th, 1920, to April 8th, 1921.

The administration of soamin and of antimony oxide were stopped shcrtly after his admission on October 8th, 1919, tartar emetic only being given. This was administered intravenously in 2 grain doses twice a week until the end of October, 1920, and once a week from then till April 8th, 1921.

His total medicamentation with arsenical and antimonial preparations from the date of commencement, November 19th, 1918 , four days after trypanosomes were first discovered, till April 8th, 1921, has bees:

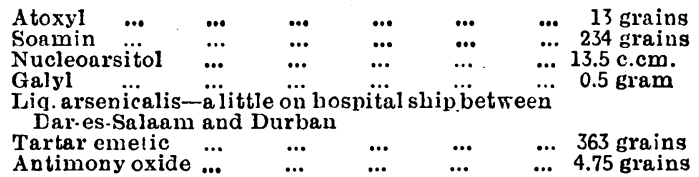

The patient was also infected with benign tertian malaria.when in East Africa. He had regalar quinine administration during most of the time he was under treatment in Durban. Dr. Murray states in his notes of July 7th, 1919: "No malarial parasites were seen in blood films since January, 1919 "; and on that date the administration of quinine was stopped.

No malarial parasites were found in the blood films while he was at the institute until, without any rise of temperature or other symptom, they were found in considerable numbers on March 17th, 1920, and in small numbers the following day. Quinine administration was recommended, and continued for a considerablexperiod. Malarial parasites have not again been seen.

His weight at the cessation of treatment was 11 st. 3 lb., which is only a few pounds under his normal pre-war weight. During treatment he had been down to as low as 10 st. $3 \mathrm{lb}$. He did a 